\title{
Tumour invasiveness, the local and systemic environment and the basis of staging systems in colorectal cancer
}

\author{
$\mathrm{J} \mathrm{H} \mathrm{Park}^{\star}{ }^{* 1,2}, \mathrm{H}$ van Wyk ${ }^{1}$, C S D Roxburgh ${ }^{1}, \mathrm{P}$ G Horgan ${ }^{1}, \mathrm{~J} \mathrm{Edwards}^{2}$ and D C McMillan ${ }^{1}$ \\ ${ }^{1}$ Academic Unit of Surgery, School of Medicine, Dentistry \& Nursing, University of Glasgow, Glasgow Royal Infirmary, \\ Glasgow G31 2ER, UK and ' Unit of Experimental Therapeutics, Institute of Cancer Sciences, University of Glasgow, Garscube \\ Estate, Glasgow G61 1BD, UK
}

Background: The present study aimed to examine the relationship between tumour invasiveness (T stage), the local and systemic environment and cancer-specific survival (CSS) of patients with primary operable colorectal cancer.

Methods: The tumour microenvironment was examined using measures of the inflammatory infiltrate (Klintrup-Makinen (KM) grade and Immunoscore), tumour stroma percentage (TSP) and tumour budding. The systemic inflammatory environment was examined using modified Glasgow Prognostic Score (mGPS) and neutrophil:lymphocyte ratio (NLR). A 5-year CSS was examined.

Results: A total of 331 patients were included. Increasing T stage was associated with colonic primary, N stage, poor differentiation, margin involvement and venous invasion $(P<0.05)$. T stage was significantly associated with $\mathrm{KM}$ grade $(P=0.001)$, Immunoscore $(P=0.016)$, TSP $(P=0.006)$, tumour budding $(P<0.001)$, and elevated mGPS and NLR (both $P<0.05)$. In patients with T3 cancer, $N$ stage stratified survival from 88 to $64 \%$, whereas Immunoscore and budding stratified survival from 100 to $70 \%$ and from 91 to $56 \%$, respectively. The Glasgow Microenvironment Score, a score based on KM grade and TSP, stratified survival from 93 to $58 \%$.

Conclusions: Although associated with increasing T stage, local and systemic tumour environment characteristics, and in particular Immunoscore, budding, TSP and mGPS, are stage-independent determinants of survival and may be utilised in the staging of patients with primary operable colorectal cancer.

The staging of patients with colorectal cancer is based on the tumour, node, metastasis (TNM) classification as described by the Union for International Cancer Control/ American Joint Committee on Cancer (UICC/AJCC). For patients without metastatic disease, prognosis is primarily determined by the depth of invasion of the primary tumour ( $\mathrm{T}$ stage) as well as the presence of regional lymph node metastases ( $\mathrm{N}$ stage). However, the use of TNM-based staging remains problematical, since increasing disease stage does not necessarily reflect a stepwise increase in risk of recurrence or death. For example, the survival of patients with Stage IIIa (T1/2, $\mathrm{N} 1)$ colon cancer is superior to that of patients with stage IIb (T4, N0) disease (O'Connell et al, 2004).
Given that TNM criteria are suboptimal, there is increasing effort to refine colorectal cancer staging. One potential approach is to examine the molecular characteristics of the tumour, and various approaches ranging from assessment of gene expression profiles to more comprehensive molecular subtyping have been described (Salazar et al, 2011; Guinney et al, 2015). These have largely failed to translate from use as clinical research tools, with the practicalities of assays employed, differing methodologies, and high costs prohibiting routine clinical use (Munro et al, 2005; Church et al, 2012). Additionally, except for assessment of KRAS status and microsatellite instability (De Roock et al, 2010; Guastadisegni et al, 2010), the clinical utility of such

*Correspondence: Dr JH Park; E-mail: james.park@glasgow.ac.uk

Received 18 January 2017; revised 4 March 2017; accepted 27 March 2017; published online 20 April 2017

(C) 2017 Cancer Research UK. All rights reserved 0007-0920/17 
characteristics as predictive markers of treatment response remain largely unknown.

A differing approach is the assessment of the local and systemic tumour environment, encompassing the interface between tumour and host (Hanahan and Weinberg, 2011; McAllister and Weinberg, 2014). Loss of local anti-tumour immune responses (Klintrup et al, 2005; Pages et al, 2009; Bindea et al, 2013), expansion of the tumour-associated stroma (Mesker et al, 2007; Huijbers et al, 2013) and the presence of tumour budding (Ueno et al, 2002), have all been identified as markers of poor prognosis. Such characteristics may be readily assessed utilising routinely available formalin-fixed paraffin-embedded specimens and pathological techniques, and have been validated as stage-independent predictors of survival. Similarly, the presence of an elevated systemic inflammatory response, as evidenced not only by circulating cytokines (Kantola et al, 2012) but also by routinely measured inflammatory mediators (McMillan, 2013), is similarly associated with poorer survival.

We have previously reported that combined assessment of the tumour inflammatory cell infiltrate (utilising both generalised inflammatory cell infiltrate and $\mathrm{CD}^{+}{ }^{+}$and $\mathrm{CD} 8{ }^{+}$T-lymphocyte subsets) and the tumour-associated stroma (using tumour stroma percentage (TSP)), hold independent and complimentary prognostic value in patients with colorectal cancer (Park et al, 2015a, b). Furthermore, the addition of tumour budding further stratifies survival independent of these two characteristics (van Wyk et al, 2016). As such, assessment of these measures, in addition to the systemic inflammatory response, provides the opportunity to utilise characteristics of both the tumour and the host to determine prognosis.

Although the presence of adverse local and systemic characteristics has been previously reported to be associated with increasing $\mathrm{T}$ stage, it is of interest that they retain independent prognostic value (Pages et al, 2005; Park et al, 2015b, 2016b; van Wyk et al, 2016). Therefore, given the routine reporting of $T$ stage, it would be of interest to examine their prognostic value relative to present TNM-based staging. As such, the aim of the present study was to examine the interrelationships between $\mathrm{T}$ stage, components of the local and systemic environment, and survival of patients undergoing potentially curative resection of primary operable colorectal cancer.

\section{PATIENTS AND METHODS}

Patients were identified from a prospectively maintained database of colorectal cancer resections in a single surgical unit in Glasgow Royal Infirmary. For the present study, patients who on the basis of pre-operative computed tomography and intra-operative findings were considered to have undergone potentially curative, elective resection of stage I-III colorectal adenocarcinoma between January 1997 and May 2008 were included. Exclusion criteria included emergency, localised or palliative resection, pre-operative chemoradiotherapy and death within 30 days of operation. Study approval was granted by the West of Scotland Research Ethics Committee.

Patients were staged according to the 5th edition of TNM criteria as is current practice in the United Kingdom (Loughrey et al, 2014). Tumours were categorised as either proximal (caecum, ascending colon, hepatic flexure and transverse colon), distal (splenic flexure, descending colon, sigmoid) or rectal (rectosigmoid and rectum) on the basis of operative and pathological reports. The presence of venous invasion was identified routinely using routine elastica staining.

Patients were followed up for a minimum of 5 years. Patients were discussed following surgery at multi-disciplinary meetings comprised of clinicians with a specialist interest in colorectal cancer, where those with stage III and high-risk stage II disease were considered for adjuvant, 5-fluoruracil-based chemotherapy according to contemporary treatment protocols. Cause and date of death were crosschecked with the cancer registration system and Registrar General (Scotland), with records complete until 31 March 2014, which acted as the censor date. Cancer-specific survival was measured from date of surgery until date of death from recurrent or metastatic colorectal cancer, and overall survival was measured until date of death from any cause.

Assessment of mismatch repair status. Mismatch repair (MMR) status was performed for a subgroup of patients who had tissue included in a tissue microarray (TMA) as previously described (Park et al, 2016a). Briefly, TMA sections were stained for MLH1, MSH6, MSH2 and PMS2. In accordance with UK NEQAS (Arends et al, 2008), tumours were considered MMR competent if tumour epithelial nuclear staining was positive, and MMR deficient if tumour epithelial staining was negative with positive staining of intratumoural lymphocytes.

Assessment of the tumour microenvironment. The generalised inflammatory cell infiltrate was examined using the KlintrupMäkinen (K-M) grade as previously described (Klintrup et al, 2005). Briefly, using H\&E-stained sections of the deepest point of tumour invasion, the density of the generalised inflammatory cell infiltrate was graded as low-grade (no increase or mild, patchy increase in inflammatory cells) or high-grade (prominent inflammatory reaction, forming a band at the invasive margin, or florid cup-like infiltrate at the invasive edge with frequent destruction of cancer cell islands). The adaptive, T-lymphocytic infiltrate was examined as previously described (Richards et al, 2014). Briefly, full sections of the deepest point of invasion were stained for mature $\left(\mathrm{CD}^{+}\right)$and cytotoxic $\left(\mathrm{CD}^{+}\right)$T-lymphocytes and the density of each cell type within intraepithelial compartment and invasive margin semi-quantitatively graded as either high or low. The Immunoscore, a quantitative assessment of CD3 ${ }^{+}$and CD8 ${ }^{+}$ density in both regions, has previously been reported utilising automated digital pathology (Galon et al, 2014). Manual semiquantitative assessment has been shown to correlate strongly with automated assessment, while allowing for increased discrimination of non-specific background staining (De Smedt et al, 2015). As such, a semi-quantitative Immunoscore was utilised, calculated from the number of compartments with a high density of immune cells, ranging from $\operatorname{Im} 0$ (all regions low density) to $\operatorname{Im} 4$ (all regions high density). On the basis of previous work, patients were stratified into three prognostic groups: Im0/1 (low density), Im 2/3 (moderate density) and Im4 (high density; Park et al, 2015a).

Tumour stroma percentage (TSP), tumour necrosis, and tumour budding were all examined using $\mathrm{H} \& \mathrm{E}$-stained sections of the invasive margin as previously described (Mesker et al, 2007; Pollheimer et al, 2010; van Wyk et al, 2016). Briefly, excluding necrosis and mucin deposits, TSP was calculated as low $(<50 \%$ of tumour area) or high ( $>50 \%$ of tumour area). Tumour necrosis was graded as low (absent or $<10 \%$ of tumour area) or high ( $>10 \%$ of tumour area). To assess tumour budding, the number of tumour buds (tumour cells with up to five nuclei or single tumour cells) in 10 high-power fields was counted. On the basis of previous work, a budding count $>20$ was considered high grade (van Wyk et al, 2016).

Assessment of the systemic inflammatory response. Pre-operative serum C-reactive protein (CRP), albumin and differential white cell count were measured within 30 days prior to surgery as routine and recorded prospectively. The systemic inflammatory response was measured using the modified Glasgow Prognostic Score (mGPS) and neutrophil:lymphocyte ratio (NLR) as previously described (Guthrie et al, 2013; McMillan, 2013). Patients with $\mathrm{CRP} \leqslant 10 \mathrm{mgl}^{-1}$ were given a score of 0 , patients with CRP $>10 \mathrm{mgl}^{-1}$ a score of 1 , and patients with CRP $>10 \mathrm{mgl}^{-1}$ 
and albumin $<35 \mathrm{gl}^{-1}$ a score of 2 . On the basis of previous literature review, NLR $>5$ was considered elevated (Guthrie et al, 2013).

Statistical analysis. The relationship between $\mathrm{T}$ stage and characteristics of the local and systemic environments was examined using the $\chi^{2}$-test for linear trend. Their relationship and cancer-specific and overall survival was examined using Kaplan-Meier log-rank analysis to calculated five-year survival (standard error (s.e.)). Variables associated with survival were entered into a Cox proportional hazards regression analysis using a backwards-conditional method. A $P$-value $\leqslant 0.05$ was considered statistically significant. All statistical analyses were performed using SPSS version 22.0 (IBM SPSS, Armonk, NY, USA).

\section{RESULTS}

A total of 331 patients were included. Two-thirds of patients were 65 or older at time of surgery and $52 \%$ were male. Thirty percent of patients underwent resection of rectal cancer. Eighty-two patients received adjuvant therapy. The majority of patients (90\%) had a tumour breaching through muscularis propria, with 208 and 90 patients with T3 and T4 tumours respectively. Of the remaining patients, eight had a T1 tumour and 25 had a T2 tumour.

The relationship between $\mathrm{T}$ stage and clinicopathological characteristics is displayed in Table 1 . T stage was associated with colonic primary $(P<0.001), \mathrm{N}$ stage $(P<0.01)$, margin involvement, venous invasion (both $P<0.001$ ), and poor differentiation $(P<0.05)$. In addition, $\mathrm{T}$ stage was associated with adjuvant chemotherapy $(P<0.05)$ but not age or sex. Mismatch repair status was available for 209 patients, and was not associated with increasing $\mathrm{T}$ stage.

The relationship between $\mathrm{T}$ stage and the local and systemic environment was examined (Table 2). T stage was associated with high-grade necrosis, infiltrative invasive margin, high-grade tumour budding, low $\mathrm{K}-\mathrm{M}$ grade (all $P \leqslant 0.001$ ) and high TSP $(P<0.01)$. Furthermore, increasing $\mathrm{T}$ stage was associated with lower Immunoscore and elevated systemic inflammatory responses as measured by mGPS and NLR (all $P<0.05$ ). Certain characteristics appeared to become more prevalent earlier than others; there was a statistically significant increase in the number of patients with high-grade necrosis and low $\mathrm{K}-\mathrm{M}$ grade observed in the shift from T2 to T3 (Bonferroni-corrected $P<0.05$ ), whereas the proportion of patients with an infiltrative margin, high-grade budding and high TSP showed a statistically greater increase between T3 to T4 $(P<0.05)$. Although an elevated mGPS and NLR showed a greater stepwise increase between $\mathrm{T} 3$ to $\mathrm{T} 4$, this did not reach statistical significance.

The relationship between tumour site, $\mathrm{T}$ stage and the local and systemic environment was examined (Supplementary Table 1). In patients with cancer of the right colon, increasing $\mathrm{T}$ stage was associated with tumour budding and TSP (both $P<0.01$ ), and showed a trend towards an association with necrosis $(P=0.054)$ and an infiltrative margin $(P=0.081)$. In patients with cancer of the left colon, increasing $\mathrm{T}$ stage was associated with necrosis $(P<0.01)$, an infiltrative margin $(P<0.05)$ and tumour budding $(P<0.001)$. In patients with rectal cancer, increasing $\mathrm{T}$ stage was associated with an infiltrative margin, weak K-M grade (both $P \leqslant 0.001)$ and showed a trend towards weak Immunoscore $(P=0.096)$.

The relationship between the local and systemic tumour environment and 5-year survival was examined (Table 3). The median follow-up of survivors was 134 months (interquartile range 108-170 months) with 96 cancer deaths and 105 non-cancer deaths. Five-year cancer-specific survival of the whole cohort was $77 \%$. N stage, character of margin, budding, $\mathrm{K}-\mathrm{M}$ grade, TSP,
Table 1. The relationship between $\mathrm{T}$ stage and clinicopathological characteristics of patients undergoing elective, primary resection of stage I-III colorectal cancer

\begin{tabular}{|c|c|c|c|c|c|}
\hline & $\begin{array}{c}\text { T1 } \\
N=8 \\
(\%)\end{array}$ & $\begin{array}{c}\text { T2 } \\
N=25 \\
(\%)\end{array}$ & $\begin{array}{c}\text { T3 } \\
N=208 \\
(\%)\end{array}$ & $\begin{array}{c}\text { T4 } \\
N=90 \\
(\%)\end{array}$ & $P$ \\
\hline \multicolumn{6}{|c|}{ Host characteristics } \\
\hline Age & & & & & 0.713 \\
\hline$<65$ & $1(13)$ & $9(36)$ & $69(33)$ & $33(37)$ & \\
\hline $65-74$ & $5(62)$ & $8(32)$ & $70(34)$ & $27(30)$ & \\
\hline$>75$ & $2(25)$ & $8(32)$ & $69(33)$ & $30(33)$ & \\
\hline Sex & & & & & 0.533 \\
\hline Female & $5(62)$ & $16(64)$ & $93(45)$ & $46(51)$ & \\
\hline Male & $3(38)$ & $9(36)$ & $115(55)$ & $44(49)$ & \\
\hline $\begin{array}{c}\text { Adjuvant } \\
\text { therapy }(330)\end{array}$ & & & & & 0.030 \\
\hline $\begin{array}{l}\text { therapy }(330) \\
\text { No }\end{array}$ & $6(75)$ & $23(92)$ & $159(76)$ & $60(67)$ & \\
\hline Yes & $2(25)$ & $2(8)$ & 49 (24) & $29(33)$ & \\
\hline \multicolumn{6}{|c|}{ Tumour characteristics } \\
\hline Tumour site & & & & & $<0.001$ \\
\hline Right colon & $0(0)$ & $7(28)$ & $78(38)$ & $47(52)$ & \\
\hline Left colon & $2(25)$ & $5(20)$ & $67(32)$ & $26(29)$ & \\
\hline Rectum & $6(75)$ & $13(52)$ & $63(30)$ & $17(19)$ & \\
\hline $\mathrm{N}$ stage & & & & & 0.002 \\
\hline 0 & $5(62)$ & $20(80)$ & $139(67)$ & $45(50)$ & \\
\hline 1 & $3(38)$ & $4(16)$ & $56(27)$ & $32(36)$ & \\
\hline 2 & $0(0)$ & $1(4)$ & $13(6)$ & $13(14)$ & \\
\hline Tumour & & & & & 0.016 \\
\hline differentiation & & & & & \\
\hline Well/ mod & $7(87)$ & $24(96)$ & $189(91)$ & $72(80)$ & \\
\hline Poor & $1(13)$ & $1(4)$ & $19(9)$ & $18(20)$ & \\
\hline Margin & & & & & $<0.001$ \\
\hline involvement & & & & & \\
\hline Absent & $8(100)$ & $25(100)$ & 205 (99) & $72(80)$ & \\
\hline Present & $0(0)$ & $0(0)$ & $3(1)$ & $18(20)$ & \\
\hline Venous & & & & & $<0.001$ \\
\hline \multicolumn{6}{|l|}{ invasion } \\
\hline Absent & $8(100)$ & $23(92)$ & $140(67)$ & $45(50)$ & \\
\hline Present & $0(0)$ & $2(8)$ & $68(33)$ & $45(50)$ & \\
\hline Mismatch & & & & & 0.161 \\
\hline \multicolumn{6}{|l|}{$\begin{array}{l}\text { repair status } \\
(209)\end{array}$} \\
\hline Competent & $7(87)$ & $15(88)$ & $110(87)$ & $44(77)$ & \\
\hline Deficient & $1(13)$ & $2(12)$ & $17(13)$ & $13(23)$ & \\
\hline
\end{tabular}

Immunoscore and mGPS all stratified 5-year cancer-specific survival (all $P<0.001$ ), whereas tumour necrosis, the NLR and MMR status did not. On multivariate analysis (Table 4), controlling for age, adjuvant chemotherapy, T stage and venous invasion, tumour budding, Immunoscore and mGPS remained independently associated with survival, whereas $\mathrm{N}$ stage, character of margin and $\mathrm{K}-\mathrm{M}$ grade did not; TSP showed a non-significant association with survival (HR 1.64, $P=0.084)$.

Five-year overall survival was $65 \%$ (Table 3). N stage, necrosis, budding, $\mathrm{K}-\mathrm{M}$ grade, TSP, Immunoscore and mGPS (all $P<0.05$ ), but not MMR status, character of margin or NLR stratified fiveyear overall survival. On multivariate analysis (Table 4), controlling for age, adjuvant therapy, $\mathrm{T}$ stage and venous invasion, tumour budding, TSP and mGPS remained independently associated with survival, whereas $\mathrm{N}$ stage, necrosis and $\mathrm{K}-\mathrm{M}$ grade did not; Immunoscore showed a non-significant association with improved survival (HR: $0.77, P=0.053$ ).

As tumour budding, TSP, Immunoscore and mGPS appeared to be consistently associated with both cancer-specific and overall survival, the relationship between these characteristics, tumour site and survival was examined (Table 5). Tumour budding and mGPS were associated with both cancer-specific and overall survival across all tumour sites. Tumour stroma percentage showed an association with cancer-specific survival across all tumour sites, but only appeared to stratify overall survival of patients with right 
Table 2. The relationship between $T$ stage, the tumour microenvironment and systemic environment of patients undergoing elective, primary resection of stage I-III colorectal cancer

\begin{tabular}{|c|c|c|c|c|c|}
\hline & $\begin{array}{c}\text { T1 (\%) } \\
N=8 \\
(\%)\end{array}$ & $\begin{array}{c}\text { T2 (\%) } \\
N=25 \\
(\%)\end{array}$ & $\begin{array}{c}\text { T3 (\%) } \\
N=208 \\
(\%)\end{array}$ & $\begin{array}{c}\mathrm{T} 4(\%) \\
N=90 \\
(\%)\end{array}$ & $P$ \\
\hline \multicolumn{6}{|c|}{ Tumour microenvironment } \\
\hline Necrosis (297) & & & & & $<0.001$ \\
\hline Absent & $7(87)$ & $19(90)$ & $106(56)$ & $37(46)$ & \\
\hline Present & $1(13)$ & $2(10)$ & $82(44)$ & $43(54)$ & \\
\hline Invasive margin (312) & & & & & $<0.001$ \\
\hline Expansile & $7(87)$ & $18(82)$ & $119(60)$ & $34(40)$ & \\
\hline Infiltrative & $1(13)$ & $4(18)$ & $78(40)$ & $51(60)$ & \\
\hline Tumour budding (302) & & & & & $<0.001$ \\
\hline Low & $5(71)$ & $18(78)$ & $146(74)$ & $33(43)$ & \\
\hline High & $2(29)$ & $5(22)$ & $50(26)$ & $43(57)$ & \\
\hline $\begin{array}{l}\text { Klintrup-Mäkinen } \\
\text { grade (307) }\end{array}$ & & & & & 0.001 \\
\hline Strong & $5(62)$ & $14(67)$ & $63(32)$ & $21(26)$ & \\
\hline Weak & $3(38)$ & $7(33)$ & $133(68)$ & $61(74)$ & \\
\hline $\begin{array}{l}\text { Tumour stroma } \\
\text { percentage (331) }\end{array}$ & & & & & 0.006 \\
\hline Low & $7(87)$ & $19(76)$ & $168(81)$ & $56(62)$ & \\
\hline High & $1(13)$ & $6(24)$ & 40 (19) & $34(38)$ & \\
\hline Immunoscore (226) & & & & & 0.016 \\
\hline $0-1$ & $2(29)$ & $8(42)$ & 68 (49) & $37(61)$ & \\
\hline $2-3$ & $2(29)$ & 7 (37) & $54(39)$ & $17(28)$ & \\
\hline 4 & $3(42)$ & $4(21)$ & $17(12)$ & $7(12)$ & \\
\hline \multicolumn{6}{|l|}{ Systemic environment } \\
\hline mGPS (330) & & & & & 0.031 \\
\hline 0 & $6(75)$ & $16(64)$ & $127(61)$ & $45(51)$ & \\
\hline 1 & $2(25)$ & $8(32)$ & $51(25)$ & $29(33)$ & \\
\hline 2 & $0(0)$ & $1(4)$ & $30(14)$ & $15(17)$ & \\
\hline NLR (225) & & & & & 0.033 \\
\hline$\leqslant 5$ & $6(86)$ & $17(85)$ & $115(82)$ & $39(67)$ & \\
\hline$>5$ & $1(14)$ & $3(15)$ & $25(18)$ & $19(33)$ & \\
\hline
\end{tabular}

and left colonic cancer but not rectal cancer. Immunoscore was associated with cancer-specific and overall survival of patients with right-sided and rectal cancers; although appearing to stratify cancer-specific and overall survival of patients with left colonic cancers, this did not reach statistical significance.

\section{DISCUSSION}

The results of the present study confirm the relationship between tumour invasion and the presence of adverse characteristics within the local and systemic environment. Such characteristics, namely tumour budding, TSP, Immunoscore and the mGPS, appeared to have greater prognostic value than evaluation of $\mathrm{N}$ stage in patients with primary operable colorectal cancer.

Advancing $\mathrm{T}$ stage correlated significantly with the presence of an increasingly tumour-supportive microenvironment as evidenced by loss of host immune responses, expansion of the tumour-associated stroma and the presence of tumour budding. This is consistent with previous work, whereby such adverse characteristics become more prevalent with increasing tumour size and depth of invasion (Bindea et al, 2013; Park et al, 2015b; Vayrynen et al, 2016). It was of interest, however, that the progression of each of these characteristics appeared to occur in a stepwise manner, with the proportion of some appearing to increase at an earlier $\mathrm{T}$ stage than others. For example, attenuation of the generalised local inflammatory cell infiltrate appeared to occur at a relatively early stage (between T2 and T3), whereas the presence of tumour budding and increasing TSP appeared to occur
Table 3. The relationship between tumour, microenvironment and systemic environment characteristics of patients

undergoing elective, primary resection of stage I-III colorectal cancer and five-year cancer-specific and overall survival

\begin{tabular}{|c|c|c|c|c|}
\hline & $\begin{array}{c}\text { 5-yr CSS } \\
\% \text { (s.e.) }\end{array}$ & $P$ & $\begin{array}{c}5-\mathrm{yr} \text { OS \% } \\
\text { (s.e.) }\end{array}$ & $P$ \\
\hline All & 77 (2) & - & 65 (3) & - \\
\hline $\begin{array}{c}\text { N stage } \\
\text { N0 } \\
\text { N1 } \\
\text { N2 }\end{array}$ & $\begin{array}{l}86(2) \\
64(5) \\
46(10)\end{array}$ & $<0.001$ & $\begin{array}{l}74(3) \\
56(5) \\
33(9)\end{array}$ & 0.011 \\
\hline $\begin{array}{l}\text { Mismatch repair status } \\
\text { Deficient } \\
\text { Competent }\end{array}$ & $\begin{array}{l}88(6) \\
73(3)\end{array}$ & 0.100 & $\begin{array}{l}79(7) \\
62(4)\end{array}$ & 0.551 \\
\hline $\begin{array}{l}\text { Necrosis } \\
\text { Absent } \\
\text { Present }\end{array}$ & $\begin{array}{l}80(3) \\
72(4)\end{array}$ & 0.130 & $\begin{array}{l}75(3) \\
53(4)\end{array}$ & 0.001 \\
\hline $\begin{array}{l}\text { Margin } \\
\text { Expansile } \\
\text { Infiltrative }\end{array}$ & $\begin{array}{l}82(3) \\
69(4)\end{array}$ & $<0.001$ & $\begin{array}{l}69(3) \\
60(4)\end{array}$ & 0.269 \\
\hline $\begin{array}{l}\text { Tumour budding } \\
\text { Low } \\
\text { High }\end{array}$ & $\begin{array}{l}90(2) \\
54(5)\end{array}$ & $<0.001$ & $\begin{array}{l}75(3) \\
49(5)\end{array}$ & $<0.001$ \\
\hline $\begin{array}{l}\text { Klintrup-Mäkinen } \\
\text { grade } \\
\text { Strong } \\
\text { Weak }\end{array}$ & $\begin{array}{l}90(3) \\
70(3)\end{array}$ & $<0.001$ & $\begin{array}{l}78(4) \\
59(3)\end{array}$ & 0.004 \\
\hline $\begin{array}{l}\text { Tumour stroma } \\
\text { percentage } \\
\text { Low } \\
\text { High }\end{array}$ & $\begin{array}{l}81(3) \\
64(6)\end{array}$ & $<0.001$ & $\begin{array}{l}69(3) \\
53(6)\end{array}$ & 0.015 \\
\hline $\begin{array}{l}\text { Immunoscore } \\
4 \\
2-3 \\
0-1\end{array}$ & $\begin{array}{l}96(3) \\
87(4) \\
62(5)\end{array}$ & $<0.001$ & $\begin{array}{l}84(7) \\
75(5) \\
51(5)\end{array}$ & $<0.001$ \\
\hline $\begin{array}{l}\text { Modified Glasgow } \\
\text { prognostic score } \\
0 \\
1 \\
2\end{array}$ & $\begin{array}{l}83(3) \\
72(5) \\
57(8)\end{array}$ & $<0.001$ & $\begin{array}{l}75(3) \\
57(5) \\
39(7)\end{array}$ & $<0.001$ \\
\hline $\begin{array}{l}\text { Neutrophil: } \\
\text { lymphocyte ratio } \\
\quad \leqslant 5 \\
>5\end{array}$ & $\begin{array}{l}79(3) \\
73(7)\end{array}$ & 0.362 & $\begin{array}{l}70(3) \\
56(7)\end{array}$ & 0.080 \\
\hline
\end{tabular}

later, with a clear stepwise change evident between T3 and T4 tumours.

Although based on observational data, the present results potentially inform our understanding of the nature of the tumour microenvironment and its development in patients with colorectal cancer. Loss of adaptive, anti-tumour immune responses, or 'immune escape' may be the initial precipitant, allowing sustained tumour growth and invasion (Mlecnik et al, 2011), with other adverse tumour microenvironment characteristics developing further downstream in the presence of 'pro-tumour' local and systemic immune responses (McAllister and Weinberg, 2014). Certainly, it is recognised that the immune microenvironment evolves in tandem with stage progression, favouring the development of a more pro-tumour 'immunome' as T stage increases (Bindea et al, 2013). As this progresses and anti-tumour immunity is degraded, it may allow the development of further pro-tumour microenvironment characteristics such as recruitment and activation of tumour-associated fibroblasts (Chrysanthopoulou et al, 2014) and budding (Koelzer et al, 2015).

Subgroup analysis found that the relationship between $\mathrm{T}$ stage, and local and systemic environment characteristics was not consistent across tumour sites. In patients with right-sided 
Table 4. The relationship between $\mathbf{N}$ stage, the tumour microenvironment and systemic environment and cancer-specific and overall survival of patients undergoing elective, primary resection of stage I-III colorectal cancer

Multivariate survival analysis $(\mathrm{HR}, 95 \% \mathrm{Cl})$

\begin{tabular}{|c|c|c|c|c|}
\hline Characteristic & Cancer-specific survival & $P$ & Overall survival & $P$ \\
\hline $\mathrm{N}$ stage $(0 / 1 / 2)$ & $1.04(0.71-1.52)$ & 0.836 & $1.10(0.83-1.47)$ & 0.509 \\
\hline Necrosis (absent/ present) & - & - & $1.40(0.97-2.02)$ & 0.074 \\
\hline Margin (expansile/ infiltrative) & $1.29(0.73-2.27)$ & 0.388 & - & - \\
\hline Budding (absent/ present) & $2.80(1.58-4.94)$ & $<0.001$ & $1.56(1.07-2.27)$ & 0.021 \\
\hline Klintrup-Mäkinen grade (strong/ weak) & $1.18(0.58-2.41)$ & 0.650 & $1.20(0.78-1.83)$ & 0.406 \\
\hline Tumour stroma percentage (low/ high) & $1.64(0.94-2.88)$ & 0.084 & $1.89(1.25-2.84)$ & 0.002 \\
\hline Immunoscore (0-1/2-3/4) & $0.41(0.25-0.67)$ & $<0.001$ & $0.77(0.59-1.00)$ & 0.053 \\
\hline mGPS (0/ 1/ 2) & $1.55(1.08-2.23)$ & 0.017 & $1.46(1.14-1.88)$ & 0.003 \\
\hline
\end{tabular}

Abbreviations: $\mathrm{Cl}=$ confidence intervals; $\mathrm{HR}=$ hazards ratio; $\mathrm{mGPS}=$ modified Glasgow Prognostic Score. Multivariate analysis performed controlling for age, tumour site, adjuvant therapy use, $T$ stage and venous invasion.

Table 5. The relationship between local and systemic environment characteristics, tumour site, and five-year cancer-specific and overall survival of patients undergoing elective, primary resection of stage I-III colorectal cancer

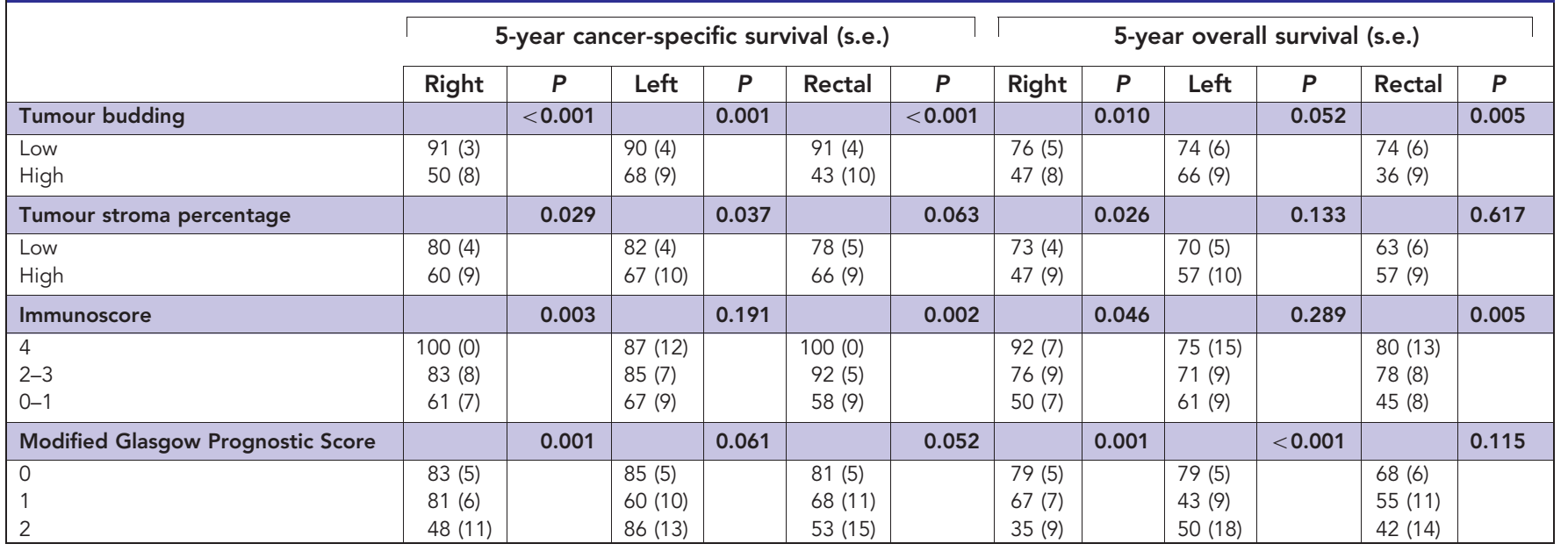

tumours, increasing T stage was associated with increasing TSP but not loss of the inflammatory cell infiltrate; conversely, the opposite was found in patients with rectal cancer. This may reflect the molecular heterogeneity of tumour arising from different sites (Birkenkamp-Demtroder et al, 2005), with tumour microenvironment characteristics such as necrosis, mesenchymal and inflammatory cell infiltration being associated with distinct molecular characteristics (Guinney et al, 2015; Vayrynen et al, 2016). Consistent with this, in the present study, MMR deficiency was identified in $30 \%$ of right-sided cancers compared to only $6 \%$ of rectal cancers $(P<0.001)$.

Subsequent revisions of the TNM staging system have introduced significant changes to pathological definitions, particularly with respect to nodal stage and often with little supporting evidence (Quirke et al, 2007). Such changes have led to concern regarding the potential 'upstaging of patients' (Nagtegaal et al, 2011; Ueno et al, 2012). Given that the criteria for T stage remains relatively standardised and largely unchanged since first described by Dukes (Dukes, 1932), it presents an attractive and logical foundation to base disease staging upon. It has previously been proposed that staging should be weighted more towards $\mathrm{T}$ stage, with less reliance on the presence of nodal involvement as a defining factor for high-risk disease (Gunderson et al, 2010; Li et al, 2016). However, although associated with increasing T stage, when controlling for $\mathrm{T}$ stage, $\mathrm{N}$ stage and venous invasion, assessment of local and systemic environment characteristics were independently associated with survival. Indeed, such characteristics may further stratify $\mathrm{T}$ stage in terms of survival. For example, the presence of budding, an expanded stroma and loss of the local immune response may identify patients with $\mathrm{T} 1 / 2$ tumours with poorer survival. If this were proven to be the case, then such characteristics may aid, for example, in the decision between polypectomy rather than formal segmental resection in patients with polyp cancers.

In addition to MMR status, numerous other molecular characteristics have been confirmed to hold prognostic value in patients with colorectal cancer (Guinney et al, 2015; Sinicrope et al, 2015). However, these are not uniformly employed in routine clinical practice and remain costly. Therefore, it was of interest that assessment of the local and systemic environment was of greater prognostic value than MMR status. Furthermore, prognostic utility appeared consistent across different tumour sites, suggesting that molecular heterogeneity may not confound the present results. This further supports results of previous studies, whereby assessment of local and systemic inflammatory profiles, tumourassociated stroma and tumour budding have been shown to hold prognostic value independent of both MMR status (Huijbers et al, 2013; Rozek et al, 2016; Park et al, 2016a), and more extensive molecular characterisation (Ogino et al, 2009). Indeed, the relatively simple methodologies employed in the present study, and their reliance on routine pathological specimens, would make them attractive candidates for widespread clinical use. 
The relatively small number of patients with T1/2 disease limits the present study. Indeed, validation in a larger cohort, encompassing patient with earlier stage disease is warranted. Furthermore, it was not possible to examine the predictive value of local and systemic environment characteristics with respect to the use of adjuvant chemotherapy. Whether the tumour and host factors examined in the present study may be utilised in such a manner would be of considerable interest.

In conclusion, the local and systemic environment, although associated with increasing $\mathrm{T}$ stage, have independent prognostic value. In particular, the Immunoscore, tumour budding, TSP and the mGPS may be effectively employed in the staging of patients with primary operable colorectal cancer.

\section{ACKNOWLEDGEMENTS}

We acknowledge the vital contribution of Professor Alan Foulis, Dr James Going, Mr Colin Richards, Mr Graeme Guthrie, Mr Arfon Powell and the colorectal surgeon of Glasgow Royal Infirmary.

\section{CONFLICT OF INTEREST}

The authors declare no conflict of interest.

\section{REFERENCES}

Arends M, Ibrahim M, Happerfield L, Frayling I, Miller K (2008) Interpretation of immunohistochemical analysis of mismatch repair (MMR) protein expression in tissue sections for investigation of suspected Lynch/Hereditary Non-Polyposis Colorectal Cancer (HNPCC) syndrome. UK NEQAS ICC ISH Recommendations. 1.

Bindea G, Mlecnik B, Tosolini M, Kirilovsky A, Waldner M, Obenauf AC, Angell H, Fredriksen T, Lafontaine L, Berger A, Bruneval P, Fridman WH, Becker C, Pages F, Speicher MR, Trajanoski Z, Galon J (2013) Spatiotemporal dynamics of intratumoral immune cells reveal the immune landscape in human cancer. Immunity 39(4): 782-795.

Birkenkamp-Demtroder K, Olesen SH, Sorensen FB, Laurberg S, Laiho P, Aaltonen LA, Orntoft TF (2005) Differential gene expression in colon cancer of the caecum versus the sigmoid and rectosigmoid. Gut 54(3): 374-384.

Chrysanthopoulou A, Mitroulis I, Apostolidou E, Arelaki S, Mikroulis D, Konstantinidis T, Sivridis E, Koffa M, Giatromanolaki A, Boumpas DT, Ritis K, Kambas K (2014) Neutrophil extracellular traps promote differentiation and function of fibroblasts. J Pathol 233(3): 294-307.

Church D, Midgley R, Kerr D (2012) Biomarkers in early-stage colorectal cancer: ready for prime time? Dig Dis 30(Suppl 2): 27-33.

De Roock W, Claes B, Bernasconi D, De Schutter J, Biesmans B, Fountzilas G, Kalogeras KT, Kotoula V, Papamichael D, Laurent-Puig P,

Penault-Llorca F, Rougier P, Vincenzi B, Santini D, Tonini G, Cappuzzo F, Frattini M, Molinari F, Saletti P, De Dosso S, Martini M, Bardelli A, Siena S, Sartore-Bianchi A, Tabernero J, Macarulla T, Di Fiore F, Gangloff AO, Ciardiello F, Pfeiffer P, Qvortrup C, Hansen TP,

Van Cutsem E, Piessevaux H, Lambrechts D, Delorenzi M, Tejpar S (2010) Effects of KRAS, BRAF, NRAS, and PIK3CA mutations on the efficacy of cetuximab plus chemotherapy in chemotherapy-refractory metastatic colorectal cancer: a retrospective consortium analysis. Lancet Oncol 11(8): 753-762.

De Smedt L, Lemahieu J, Palmans S, Govaere O, Tousseyn T, Van Cutsem E, Prenen H, Tejpar S, Spaepen M, Matthijs G, Decaestecker C, Moles Lopez X, Demetter P, Salmon I, Sagaert X (2015) Microsatellite instable vs stable colon carcinomas: analysis of tumour heterogeneity, inflammation and angiogenesis. Br J Cancer 113(3): 500-509.

Dukes CE (1932) The classification of cancer of the rectum. J Pathol 35: 323-332.

Galon J, Mlecnik B, Bindea G, Angell HK, Berger A, Lagorce C, Lugli A, Zlobec I, Hartmann A, Bifulco C, Nagtegaal ID, Palmqvist R, Masucci GV, Botti G, Tatangelo F, Delrio P, Maio M, Laghi L, Grizzi F, Asslaber M,
D’Arrigo C, Vidal-Vanaclocha F, Zavadova E, Chouchane L, Ohashi PS, Hafezi-Bakhtiari S, Wouters BG, Roehrl M, Nguyen L, Kawakami Y, Hazama S, Okuno K, Ogino S, Gibbs P, Waring P, Sato N, Torigoe T, Itoh K, Patel PS, Shukla SN, Wang Y, Kopetz S, Sinicrope FA, Scripcariu V, Ascierto PA, Marincola FM, Fox BA, Pages F (2014) Towards the introduction of the 'Immunoscore' in the classification of malignant tumours. J Pathol 232(2): 199-209.

Guastadisegni C, Colafranceschi M, Ottini L, Dogliotti E (2010) Microsatellite instability as a marker of prognosis and response to therapy: a metaanalysis of colorectal cancer survival data. Eur J Cancer 46(15): 2788-2798. Guinney J, Dienstmann R, Wang X, de Reynies A, Schlicker A, Soneson C, Marisa L, Roepman P, Nyamundanda G, Angelino P, Bot BM, Morris JS, Simon IM, Gerster S, Fessler E, De Sousa EMF, Missiaglia E, Ramay H, Barras D, Homicsko K, Maru D, Manyam GC, Broom B, Boige V, Perez-Villamil B, Laderas T, Salazar R, Gray JW, Hanahan D, Tabernero J, Bernards R, Friend SH, Laurent-Puig P, Medema JP, Sadanandam A, Wessels L, Delorenzi M, Kopetz S, Vermeulen L, Tejpar S (2015) The consensus molecular subtypes of colorectal cancer. Nat Med 21(11): $1350-1356$

Gunderson LL, Jessup JM, Sargent DJ, Greene FL, Stewart AK (2010) Revised TN categorization for colon cancer based on national survival outcomes data. J Clin Oncol 28(2): 264-271.

Guthrie GJ, Charles KA, Roxburgh CS, Horgan PG, McMillan DC, Clarke SJ (2013) The systemic inflammation-based neutrophil-lymphocyte ratio: experience in patients with cancer. Crit Rev Oncol Hematol 88(1): 218-230.

Hanahan D, Weinberg RA (2011) Hallmarks of cancer: the next generation. Cell 144(5): 646-674.

Huijbers A, Tollenaar RA, v Pelt GW, Zeestraten EC, Dutton S, McConkey CC, Domingo E, Smit VT, Midgley R, Warren BF, Johnstone EC, Kerr DJ, Mesker WE (2013) The proportion of tumorstroma as a strong prognosticator for stage II and III colon cancer patients: validation in the VICTOR trial. Ann Oncol 24(1): 179-185.

Kantola T, Klintrup K, Vayrynen JP, Vornanen J, Bloigu R, Karhu T, Herzig KH, Napankangas J, Makela J, Karttunen TJ, Tuomisto A, Makinen MJ (2012) Stage-dependent alterations of the serum cytokine pattern in colorectal carcinoma. Br J Cancer 107(10): 1729-1736.

Klintrup K, Makinen JM, Kauppila S, Vare PO, Melkko J, Tuominen H, Tuppurainen K, Makela J, Karttunen TJ, Makinen MJ (2005) Inflammation and prognosis in colorectal cancer. Eur J Cancer 41(17): 2645-2654.

Koelzer VH, Dawson H, Andersson E, Karamitopoulou E, Masucci GV, Lugli A, Zlobec I (2015) Active immunosurveillance in the tumor microenvironment of colorectal cancer is associated with low frequency tumor budding and improved outcome. Transl Res 166(2): 207-217.

Li J, Yi CH, Hu YT, Li JS, Yuan Y, Zhang SZ, Zheng S, Ding KF (2016) TNM staging of colorectal cancer should be reconsidered according to weighting of the T stage: verification based on a 25 -year follow-up. Medicine 95(6): e2711.

Loughrey MB, Quirke P, Shepherd NA (2014) Dataset for Colorectal Cancer Histopathology Reports, 3 edn. The Royal College of Pathologists.

McAllister SS, Weinberg RA (2014) The tumour-induced systemic environment as a critical regulator of cancer progression and metastasis. Nat Cell Biol 16(8): 717-727.

McMillan DC (2013) The systemic inflammation-based Glasgow Prognostic Score: a decade of experience in patients with cancer. Cancer Treat Rev 39(5): 534-540.

Mesker WE, Junggeburt JM, Szuhai K, de Heer P, Morreau H, Tanke HJ, Tollenaar RA (2007) The carcinoma-stromal ratio of colon carcinoma is an independent factor for survival compared to lymph node status and tumor stage. Cell Oncol 29(5): 387-398.

Mlecnik B, Tosolini M, Kirilovsky A, Berger A, Bindea G, Meatchi T, Bruneval P, Trajanoski Z, Fridman WH, Pages F, Galon J (2011) Histopathologic-based prognostic factors of colorectal cancers are associated with the state of the local immune reaction. J Clin Oncol 29(6): 610-618.

Munro AJ, Lain S, Lane DP (2005) P53 abnormalities and outcomes in colorectal cancer: a systematic review. Br J Cancer 92(3): 434-444.

Nagtegaal ID, Tot T, Jayne DG, McShane P, Nihlberg A, Marshall HC, Pahlman L, Brown JM, Guillou PJ, Quirke P (2011) Lymph nodes, tumor deposits, and TNM: are we getting better? J Clin Oncol 29(18): 2487-2492.

O'Connell JB, Maggard MA, Ko CY (2004) Colon cancer survival rates with the new American Joint Committee on Cancer sixth edition staging. J Natl Cancer Inst 96(19): 1420-1425. 
Ogino S, Nosho K, Irahara N, Meyerhardt JA, Baba Y, Shima K, Glickman JN, Ferrone CR, Mino-Kenudson M, Tanaka N, Dranoff G, Giovannucci EL, Fuchs CS (2009) Lymphocytic reaction to colorectal cancer is associated with longer survival, independent of lymph node count, microsatellite instability, and CpG island methylator phenotype. Clin Cancer Res 15(20): 6412-6420.

Pages F, Berger A, Camus M, Sanchez-Cabo F, Costes A, Molidor R, Mlecnik B, Kirilovsky A, Nilsson M, Damotte D, Meatchi T, Bruneval P, Cugnenc PH, Trajanoski Z, Fridman WH, Galon J (2005) Effector memory T cells, early metastasis, and survival in colorectal cancer. $N$ Engl $J$ Med 353(25): 2654-2666.

Pages F, Kirilovsky A, Mlecnik B, Asslaber M, Tosolini M, Bindea G, Lagorce C, Wind P, Marliot F, Bruneval P, Zatloukal K, Trajanoski Z, Berger A, Fridman WH, Galon J (2009) In situ cytotoxic and memory T cells predict outcome in patients with early-stage colorectal cancer. J Clin Oncol 27(35): 5944-5951.

Park JH, McMillan DC, Edwards J, Horgan PG, Roxburgh CSD (2015a) Comparison of the prognostic value of measures of the tumor inflammatory cell infiltrate and tumor-associated stroma in patients with primary operable colorectal cancer. Oncoimmunology 5(3): e1098801. eCollection 2016.

Park JH, McMillan DC, Powell AG, Richards CH, Horgan PG, Edwards J, Roxburgh CS (2015b) Evaluation of a tumor microenvironment-based prognostic score in primary operable colorectal cancer. Clin Cancer Res 21(4): 882-888.

Park JH, Powell AG, Roxburgh CS, Horgan PG, McMillan DC, Edwards J (2016a) Mismatch repair status in patients with primary operable colorectal cancer: associations with the local and systemic tumour environment. Br J Cancer 114(5): 562-570.

Park JH, Watt DG, Roxburgh CS, Horgan PG, McMillan DC (2016b) Colorectal Cancer, Systemic Inflammation, and Outcome: Staging the Tumor and Staging the Host. Ann Surg 263(2): 326-336.

Pollheimer MJ, Kornprat P, Lindtner RA, Harbaum L, Schlemmer A, Rehak P, Langner C (2010) Tumor necrosis is a new promising prognostic factor in colorectal cancer. Hum Pathol 41(12): 1749-1757.

Quirke P, Williams GT, Ectors N, Ensari A, Piard F, Nagtegaal I (2007) The future of the TNM staging system in colorectal cancer: time for a debate? Lancet Oncol 8(7): 651-657.
Richards CH, Roxburgh CS, Powell AG, Foulis AK, Horgan PG, McMillan DC (2014) The clinical utility of the local inflammatory response in colorectal cancer. Eur J Cancer 50(2): 309-319.

Rozek LS, Schmit SL, Greenson JK, Tomsho LP, Rennert HS, Rennert G, Gruber SB (2016) Tumor-infiltrating lymphocytes, crohn's-like lymphoid reaction, and survival from colorectal cancer. J Natl Cancer Inst 108: 8.

Salazar R, Roepman P, Capella G, Moreno V, Simon I, Dreezen C, Lopez-Doriga A, Santos C, Marijnen C, Westerga J, Bruin S, Kerr D, Kuppen P, van de Velde C, Morreau H, Van Velthuysen L, Glas AM, Van't Veer LJ, Tollenaar R (2011) Gene expression signature to improve prognosis prediction of stage II and III colorectal cancer. J Clin Oncol 29(1): 17-24.

Sinicrope FA, Shi Q, Smyrk TC, Thibodeau SN, Dienstmann R, Guinney J, Bot BM, Tejpar S, Delorenzi M, Goldberg RM, Mahoney M, Sargent DJ, Alberts SR (2015) Molecular markers identify subtypes of stage III colon cancer associated with patient outcomes. Gastroenterology 148(1): $88-99$.

Ueno H, Mochizuki H, Akagi Y, Kusumi T, Yamada K, Ikegami M, Kawachi H, Kameoka S, Ohkura Y, Masaki T, Kushima R, Takahashi K, Ajioka Y, Hase K, Ochiai A, Wada R, Iwaya K, Shimazaki H, Nakamura T, Sugihara K (2012) Optimal colorectal cancer staging criteria in TNM classification. J Clin Oncol 30(13): 1519-1526.

Ueno H, Murphy J, Jass JR, Mochizuki H, Talbot IC (2002) Tumour 'budding' as an index to estimate the potential of aggressiveness in rectal cancer. Histopathology 40(2): 127-132.

van Wyk HC, Park JH, Edwards J, Horgan PG, McMillan DC, Going JJ (2016) The relationship between tumour budding, the tumour microenvironment and survival in patients with primary operable colorectal cancer. $\mathrm{Br} J$ Cancer 115(2): 156-163.

Vayrynen SA, Vayrynen JP, Klintrup K, Makela J, Karttunen TJ, Tuomisto A, Makinen MJ (2016) Clinical impact and network of determinants of tumour necrosis in colorectal cancer. Br J Cancer 114(12): 1334-1342.

This work is published under the standard license to publish agreement. After 12 months the work will become freely available and the license terms will switch to a Creative Commons AttributionNonCommercial-Share Alike 4.0 Unported License.

Supplementary Information accompanies this paper on British Journal of Cancer website (http://www.nature.com/bjc) 